\title{
ANÁLISIS EXPLORATORIO DE LOS ÁCIDOS GRASOS DEL ISAÑO (Tropaeolum tuberosum)
}

\section{Rodrigo Ramallo Zamora}

\section{RESUMEN}

Los tubérculos transformados en harina a partir de seis variedades domésticas de isaño (Tropaeolum tuberosum) fueron analizados con el fin de explorar el perfil de ácidos grasos de sus lípidos y así conocer mejor sus cualidades nutricionales. Los resultados mostraron que las harinas de isaño contienen un balance muy interesante de ácidos grasos. Los perfiles fueron muy similares entre todas las variedades analizadas. Se observó un alto contenido de ácidos grasos poliinsaturados $(70,8 \%)$, con una relación promedio insaturados/saturados de 3,0. La relación promedia linoleico/ $\alpha$-linolénico fue de 2,2. Este valor se sitúa dentro del margen recomendado para una dieta saludable $(<5)$. Sin embargo, cabe mencionar que el contenido de grasa de los tubérculos de isaño es bajo ( $<1 \%$ de la materia seca). Se debe analizar el contenido de grasa de las semillas del isaño, que podrían tener una concentración más importante de grasas. De todas maneras, los resultados son alentadores para la utilización de la planta de isaño como una fuente alimenticia.

Palabras Clave: Isaño, Tropaeolum Tuberosum, Tropaeolaceae, Cultivos Andinos, Ácidos Grasos. 